\title{
O "FIQUE EM CASA" E A INFLUÊNCIA NOS CONCEITOS MORAIS DOS PROGRAMAS INFANTIS: UM ESTUDO DO PROGRAMA "CHAVES"
}

\author{
LEONARDO, Francisco Morilhe ${ }^{1}$
}

\begin{abstract}
RESUMO: O presente estudotrabalhe visa à ênfase da importância dos programas televisivos voltados para o público infantil em tempos em que a população passa grande parte do dia em casa, devido a pandemia pelo novo coronavírus, SARS-CoV2, de modo a, de acordo com o seu conteúdo, transmitir a todos telespectadores mensagens positivas que podem influenciar em suas condutas cidadãs. Assim sendo, frisa-se, por relevante, o estudo do Programa "Chaves", transmitido no Brasil desde a década de 1980, que estimula a reflexão, utrapassando gerações, de boas maneiras que o público acata devido a influência que a mídia proporciona, pois é um veículo de suma importância que contribui para a educação e bons constumes de seus seguidores. Ademais, por ser uma ferramenta salutar nessa seara, a televisão pode se tornar grande aliada, junto à escola, na formação humanística da criança, além dos fatores afetivos que, também, podem ser captados. Assim, destacar-se-á um fator primordial para educação nacional que se trata dos programas infantis e o reflexo que estes podem proporcionar, tanto de positivo, quanto negativo, ressaltando sua contribuição para a vida dos brasileiros.
\end{abstract}

Palavras-chave: Educação. Mensagens positivas. Fatores afetivos.

\section{"STAY AT HOME" AND THE INFLUENCE ON MORAL CONCEPTS OF CHILDREN'S PROGRAMS: A STUDY OF THE "CHAVES" PROGRAM}

\begin{abstract}
SUMMARY: The present work aims to emphasize the importance of television programs aimed at children at a time when the population spends much of the day at home, due to the pandemic, in order to, according to its content, transmit messages to all viewers. that can influence their citizenship. Therefore, the study of the "Chaves" Program, which has been broadcast in Brazil since the 1980s, is relevant because it stimulates reflection, passing through generations, in good manners that the public accepts due to the influence that the media provides, because it is an extremely important vehicle that contributes to the education and goodness of its followers. Furthermore, because it is a healthy tool in this field, television can become a great ally, together with the school, in the humanistic formation of the child, in addition to the affective factors that can also be captured. Thus, a key factor for national education will be highlighted, which is about children's programs and the reflex that these can provide, both positive and negative, highlighting their contribution to the lives of brazilians.
\end{abstract}

Keywords: Education; Positive messages; Affective factors.

\section{INTRODUÇÃO}

A mídia, no Brasil, tem fator preponderante para educação das crianças, ainda mais nesse período em que há o isolamento devido a pandemia, o que leva às crianças a terem mais tempo com a televisão, por exemplo. De fato, atitudes como a transmissão de valores como companheirismo e solidariedade tornam-se protótipos nacionais. Há aqueles, contudo, a defender o isolamento a segurança como paradigma de um comportamento do brasileiro. Ora, essa crença é falaciosa, haja vista ser o povo brasileiro resultado do encontro de culturas diversas. Ademais, fortaleceu-se no país o cordialismo e atitudes afetivas como ideal, e, desse modo, não há de se falar em outra característica, senão a dos valores do coração. 
A mídia fora criada com o objetivo de integrar informativamente regiões distantes. Caracterizá-la, desse modo, permite destacar que possa ser meio de propagação de valores, tais como de cunho positivo como, por exemplo, a fraternidade, amizade e amor, e de cunho negativo, como a violência. Esse destaque, todavia, concretiza-se com o diagnóstico da influência que este veículo de comunicação possa beneficiar na educação infantil.

Considerando-se o déficit apresentado por produções midiáticas hodiernamente, devido, também, ao avanço tecnológico, a prática de assistir a um programa televisivo assume, nessa conjuntura, um caráter paradoxal no bojo da sociedade brasileira pelos conteúdos apresentados, sejam implícitos ou não, de modo a incitar atitudes ao telespectador. Outrossim, observa-se o oximoro acerca desses conteúdos, pois se de um lado contribui expressivamente para a formação cultural e educacional, de outro, entretanto, nota-se a omissão de se transmitir tais valores.

Dessa maneira, destaca-se o papel que mídia tem para contribuir com a educação em relação aos valores morais das crianças no país, onde a presente pesquisa enfatiza alguns episódios do Programa "Chaves", criado pelo autor e escritor Roberto Gomez Bolaños, falecido em 2014, e sua contribuição nesse âmbito. Assim, ele procurou, em seus roteiros, retratar personagens marginais, não no sentido "meliante" (apesar de ter feito o personagem Chompiras), mas no sentido puro do termo, do que está, de uma forma ou de outra, à margem: velhos, crianças, profissionais decadentes, malandros (KASCHNER, 2010).

Visa-se, para tanto, que o discurso humorístico contido no seriado auxiliou para seu sucesso, que se perpetua por outras gerações. Assim sendo, procura-se demonstrar de que forma o enredo simples do programa número um da televisão conseguiu conquistar legiões de admiradores ao redor do mundo e de que modo essa trama se relaciona de modo a contribuir com a educação e valores morais das crianças do Brasil.

Em suma, de frisar, por relevante, que a pesquisa realizar-se-á sob o enfoque dedutivo, a ter como início o modo de como a mídia pode influenciar o público infantil, em destaque o Programa "Chaves" e, a partir disso, ter por finalidade abstrair possíveis conclusões e basear-se-á no levantamento bibliográfico.

\section{A CULTURA MIDIÁTICA NO BRASIL}

Os meios metodológicos, entre os setores da comunicação e a educação, vêm sendo percorridos há anos, de maneira paralela, sem que os mais habilitados nesses estudos tenham chegado ao mesmo fim para a interface necessária na utilização da mídia voltada às crianças. Assim sendo, na sociedade hodierna, em que as formas comunicativas interferem diretamente no cotidiano das pessoas, independentemente da idade, não há como se negar a relevância das 
pesquisas ligadas entre essas duas searas de estudo para resultados mais eficientes nos processos escolares.

Adorno (1970) destaca que a cultura midiática tem a ver com determinada visão de mundo, com valores e comportamentos, com a absorção de padrões de gosto e de consumo, com a internalização de "imagens de felicidade" e promessas de realização para o ser humano, produzidas e disseminadas no capitalismo avançado por intermédio dos conglomerados empresariais da comunicação e do entretenimento, e principalmente por meio da publicidade.

Num âmbito mais amplo e necessariamente genérico, cultura midiática é a cultura do mercado pensada e produzida para ser transmitida e consumida segundo a gramática, a lógica própria, a estética e a forma de incidência e recepção peculiares ao sistema midiático cultural (ADORNO, 1970).

Nesse viés, o conceito midiático é amplo e remete a várias implicações no conceito industrial de cultura, mas permite apontar ou destacar realidades específicas da mídia atual e da cultura. Desse modo, é na infância que se inicia a aprendizagem que será para a vida toda, cujo período desperta novos horizontes. Nessa etapa, a criança começa a agir para o mundo e, assim, inicia a construção da sua forma de pensamento e atitudes e, quanto maior for estimulada, enquanto criança, melhor desenvolverá o seu crescimento intelectual, quando adulto.

Berger e Luckmann (1978) enfatizam a cultura em relação à mídia como "construção social da realidade", o que implica a criação, reprodução e difusão de sistemas de atitudes e modos de agir, de costumes e instituições, valores espirituais e materiais, devemos admitir que justamente neste âmbito se constituiu um grande e complexo mercado de "bens" simbólicos ou "textos" culturais.

É sabido que nessa etapa, o infante tem muitos estímulos, seja por conviver com pessoas ou pela interferência midiática, cujos fatores se encontram presentes cada vez mais em nosso cotidiano, no que se vê e no que se ouve. A formação intelectual nos adultos pode ser formada com a contribuição da mídia, como em propagandas, vídeos, filmes, músicas, entre outros, que os marcam em relação à formação psíquica e isso pode contribuir, de alguma forma, seja positiva ou negativa.

Nesse viés, em se tratando da influência que a mídia exerce na cultura infantil, Moreira (2003, p. 1207) aduz que:

A presença ubíqua desse sistema midiático-cultural, a sua ação pervasiva e constante e o poder simbólico de que dispõe estão provocando modificações profundas no âmbito da cultura, em todos os seus aspectos. Talvez a mais importante dessas transformações seja o fato de que a própria cultura é cada vez mais midiatizada (MOREIRA, 2003, p. 1207). 
Desde a tenra idade, o indivíduo assiste à televisão e se caracteriza como alguém que recebe ativamente alguma informação. Assim sendo, alguns pais deixam seus filhos optarem por determinados programas infantis, mas são relapsos na físcalização do conteúdo, ou seja, se é ou não de acordo com a idade, haja vista os teores televisivos são repletos de ações inadequadas.

Nesse diapasão, não se pode esquecer que o desenvolvimento das crianças tem várias fases que diferenciam do adulto. Nessa seara, o conteúdo midiático vem tendo permissões livres, pois mesmo sendo inerente a uma categoria livre, sem censura, muitas vezes, dificulta na educação infantil, já que a mídia é uma ferramenta influenciadora e de grande relevância.

Ademais, é preciso levar em consideração que as crianças são construtoras da cultura e as criam, e isso as torna seres pensantes. Assim, Pacheco (2009, p. 32) relata que:

Conhecer a criança é pensá-la como um ser social determinado historicamente [...], é pensá-la interagindo dinamicamente, influenciando e sendo influenciada [...], é pensá-la como um ser de relações que ocorrem na família, na sociedade, na comunidade. É conhecê-la em casa, na escola, na igreja, na rua, no clube, em seus grupos sociais, [...], enfim, em todas as suas atividades (PACHECO, 2009, p. 32).

Se por um lado há os defensores do meio televisivo como sendo um caminho para comunicação que é primacial para que se possa intensificar o aprendizado infantil, em relação as capacidades perceptivas e motoras, ordem social e ao ser tolerante, por outro lado, há os que criticam, pois creem que as crianças passam muito tempo vendo televisão, em vez de lerem livros e brincarem, o que pode acarretar na obesidade infantil, por exemplo, além de reduzir a interação social, serem consumistas e de não serem independentes daquilo que as propagandas transmitem.

Dentre os autores que defendem a televisão para o público infantil, Greenfield (1988, p. 06) se destaca; em seus estudos chegou a seguinte conclusão, “[...] crianças que veem muita televisão têm melhores aptidões para construir conceitos de relações espaço-temporais, para compreender as relações entre o todo e suas partes". Já Mello (2002, p. 25) acredita que [...] "o excesso de tempo diante da telinha impede que os pequenos desenvolvam outros tipos de relacionamentos, tenham outros contatos e envolvimentos culturais, lúdicos e afetivos".

Belloni (2001) enfatiza que à medida que a criança vai incorporando as imagens e modelos que muitas vezes são expostos na mídia televisiva ela tem a capacidade de utilizar-se deste, aceitar, ou mesmo recusar, assim testando seus limites. A autora acredita que as crianças que assistem à televisão têm a total liberdade para escolher o que é bom ou não para elas.

Por esse caminho, a criança pode ser um indivíduo que ainda não tenha sua formação crítica construída e ser vítima dos conteúdos propagados pela mídia, de forma negativa, gerando uma relação de empatia, menos criativas, reflexivas e de não construírem interpretações críticas.

Portanto, é necessário separar e ter conhecimento do potencial que a mídia pode oferecer na aprendizagem infantil, mas compete aos pais agirem nessa formação e terem ciência dos 
programas que seus filhos assistem, analisando os seus valores e ideais e tentando formar cidadãos críticos, aptos a averiguar, na adolescência e quando adultos, se no que assistem, há valores educacionais e morais.

\section{A CRIANÇA, MÍDIA E EDUCAÇÃO NA ATUALIDADE}

A pandemia pelo novo coronavírus vem obrigando diversos países a implementar medidas de isolamento social para evitar sua rápida disseminação (WHO, 2019). O fechamento das escolas, a necessidade de distanciamento físico, a proibição de atividades culturais presenciais, estão gerando impactos acadêmicos, sociais, econômicos e psicológicos. Os pais de crianças e adolescentes, sobrecarregados pelas mudanças de vida exigidas pela nova situação, têm também de gerenciar o dia a dia de seus filhos, minimizando o impacto das atuais circunstâncias na saúde mental das crianças e adolescentes (HUREMOVIĆ, 2019).

Portanto, um meio bem utilizado pelas crianças para se distraírem é a televisão. Eis que surge um entrave para pais e responsáveis: o que as crianças mais assistem? É sabido que, em tempos de quarentena, em se deve ficar em casa, ou seja, em isolamento social a fim de que se evite a transmissão ou contágio do COVID-19, urge o problema mundial de que nos "parece que a proteção à vida nos conduz a um único caminho: "ficar em casa" (SILVA. FERREIRA, 2020, p. 179).

É muito importante trabalhar com a mídia na escola, sejam nas mais variadas formas, como nas de comunicação em massa, já que esses meios influenciam as crianças na forma de pensar, devendo tais ideais serem articulados de modo a trazerem contribuições satisfatórias, no que diz respeito ao trabalho midiático com tal público. Em consonância com isso, Mello (2002, p. 31) contribui ao afirmar que:

Na medida em que a TV passou a ser parte da vida e da cultura das pessoas, aumentaram as expectativas e as exigências em relação ao veículo [...] começouse a exigir da TV obrigações que não lhe cabem e lhe foram atribuídas funções e papéis dos quais não se pode dar conta (MELLO, 2002, p. 31).

Nesse panorama, Popper e Condry (2007, p. 16) afirmam que "a televisão é incapaz de ensinar às crianças o que é necessário à sua educação". Os autores continuam, ao discorrer que, para que essa realidade possa mudar, todos os produtores dos programas de televisão deveriam ter consciência de que tem papel de educadores, somente pelo fato de crianças pequenas estarem assistindo a seus programas. E muitas vezes essas crianças não estão na companhia de um adulto, por isso recebem as informações e depois acabam internalizando-as, como se o que assistiram fosse a mais absoluta verdade.

Percebe-se que, as crianças gostam dos meios digitais, em todas as idades, classes sociais e cultura, mesmo nas classes sociais, economicamente elevadas, os menores também fazem o uso 
de ações diversas, como os esportes em geral, outros idiomas, todavia, a maioria do público infantil opta em assistir televisão.

A televisão e a internet têm uma função fundamental que agregam meios de aprendizagem e ao seu desenvolvimento pleno, na infância, que podem influenciar os mais vulneráveis, ou seja, os de menor idade, devido à inocência e o imaginário. Assim sendo, não se discutem novas técnicas de propaganda infantil no que diz respeito a influência direta, por exemplo.

Muitas vezes, há relatos no meio escolar que os filmes e os demais conteúdos midiáticos não são inerentes à faixa etária infantil, contudo, um grande entrave para que as crianças vejam tais programas restritos é a conivência de seus responsáveis que, na maioria das vezes, assistem programações inapropriadas, tendo menores de idade ao seu redor. Nessa linha de raciocínio, Mercado (2002, p. 15) afirma que:

Com as novas tecnologias, novas formas de aprender, novas competências são exigidas, novas formas de se realizar o trabalho pedagógico são necessárias e fundamentalmente, é necessário formar continuamente o novo professor para atuar nesse ambiente telemático, em que a tecnologia serve como mediador do processo ensino-aprendizagem (MERCADO, 2002, p. 15).

Destarte, o conteúdo inapropriado pode gerar um estímulo para criança, como em músicas, vídeos, entre outras, pois, também, podem ser excelentes meios que podem ser utilizados por professores, desde que o teor contenha algo de cunho educacional, o que contribui para o lúdico no processo de ensino e aprendizagem.

Ademais, as mídias podem fazer com que os menores possam construir um próprio conhecimento, auxiliando-os a serem cidadãos, no futuro, pensantes e críticos na sociedade, desde que a mídia seja uma aliada para o aprendizado e usada de maneira correta, a fim de estimular o cognitivo das crianças.

Assim, urge a necessidade de se saber quais contribuições realmente as mídias podem trazer para as crianças que estão em desenvolvimento, de modo a conhecer sua relevância, e sua abordagem acerca de sua influência no aprendizado, relevando as contribuições e a positividade.

Dessa maneira, Pacheco (2009) comprovou a necessidade de o sistema educativo incorporar a própria comunicação como conteúdo programático, criando oportunidade para que os alunos revejam, sob a orientação de seus professores, a produção que os meios de comunicação de massa exibem, movidos muitas vezes tão somente por critérios mercadológicos.

Assim sendo, frisa o debate acerca das estratégias empregadas pelo meio publicitário, sendo que, é importante compreender os valores sociais, culturais ou ideológicos que são transmitidos pela mídia. O público infantil pode assimilar o conhecimento e, sucessivamente, começar a entender universo que o cerca, desde que o compreenda. 
É importante lembrar que, as crianças ficam muito mais tempo assistindo televisão e na internet, do que em companhia dos seus pais, sendo tal fator um grande motivo para se ater no que se assiste, para que não ocorram casos em que a criança veja aquilo que não é permitido. Assim, Citelli (2004, p. 203) aduz que:

Por melhor e mais avançada que seja a tecnologia, ela não substitui a riqueza da convivência social. É necessário lembrar que o desenvolvimento da criança e do adolescente engloba, além do aspecto cognitivo, o lado emocional e social. É no contato com outras pessoas que as personalidades se desenvolvem, na ação e reação que provocam (CITELLI, 2004, p. 203).

Desse modo, não se devem ter críticas às crianças devido o tempo que ficam entretidos com a televisão, já que devem sempre estar sob a égide de um adulto, que possa intervir, se for necessário. Soifer (1991, p. 59) considera que "o ato de assistir programas televisivos deveria ser muito ocasional para crianças de 5 a 6 anos, já que ainda estão desenvolvendo suas funções intelectuais".

Portanto, "é importante compreender que se o conhecimento advém de experiências e que cada ser humano passa por elas diferentemente e assim extrai um conhecimento singular, para entendermos uns aos outros, deve o amor agir em consonância com todas as ciências" (SANCHES; LEONARDO, 2016, p. 338).

Pode-se concluir que, os estudos acerca da influência midiática sobre o comportamento infantil são de suma importância, uma vez que, em geral, tem influência no comportamento e refletem de forma significativa na maneira de pensar e de ser, além de influenciar a relação social.

A fim de contribuir com o melhor entendimento dos efeitos da era digital e da comunicação, principalmente a televisão internet, em relação ao público infantil, deve-se entender que tais meios não devem produzir efeitos tão negativos e que os alienam, uma vez que a responsabilidade é dos adultos.

\section{O PROGRAMA “CHAVES” NO AUXÍLIO DA EDUCAÇÃO E VALORES MORAIS}

Inicialmente, cabe destacar que, foi em 24 de agosto de 1984 que estrearam, tanto Chaves, quanto Chapolin, programas humorísticos, de origem mexicana, na grade de programação do Sistema Brasileiro de Televisão - SBT, ambos como integrantes secundários de programas de sucesso dentro da emissora (KASCHNER, 2006).

Não poderia ser tão comum que os produtores televisivos acatassem a exibição de programas humorísticos, como algum que fora passado num panorama mexicano, de cenário humilde e bem simples, com personagens revestidos de crianças, misturando um humor sem palavras de baixo calão e circense. Contudo, foi o que ocorreu na década de 1980, quando o SBT 
(Sistema Brasileiro de Televisão) comprou o seriado Chaves: "Todos achavam aquilo um seriado brega, mal feito, uma coisa sem graça" (SILVA, 2002, p. 85).

Criação do humorista Roberto Gómez Bolaños (conhecido no México como "Chespirito"), "Chaves" (adaptação do nome original "El Chavo Del Ocho"), surgiu na TV mexicana em 1971 e foi conquistando público até que em 1973 já era líder de audiência em quase toda a América Latina, chegando a ser exibido não só neste continente, mas em mais de oitenta países - tendo conquistado a liderança de audiência em todos eles - sendo dublado em idiomas como italiano, japonês, russo, coreano e árabe (VALLADARES, 1999).

Nesse sentido, hoje, mais de dezessete países exibem com êxito o seriado, obtendo audiências consideráveis. É o caso do Brasil; Chaves é transmitido pelo SBT desde 1984, praticamente sem interrupção, sempre com ótimos índices, sendo considerado por muitos o "coringa", o "santo milagreiro" de Silvio Santos (VALLADARES, 1999).

Se observados sob o viés da cultura mundial, o teor e o grandioso sucesso do Programa de Bolaños despertam o paradoxo entre suas características locais (as mexicanas) e mundiais (valores humanos universais). O ambiente narrado nos episódios é bem simples, caracterizado pela desigualdade social, já que se passa numa vila com o mesmo reflexo do prisma geopolítico e financeiro de países latino-americanos, fato em que aproxima a realidade de brasileiros e mexicanos, pois tal visão é um grande expoente que contribui para o êxito da série.

Kaschner (2010, p. 123) destaca que, sobre isso, Edgar Vivar, ator que interpreta Senhor Barriga, disse que:

Há muito mais coisas que nos unem [México e Brasil] do que nos separam, apesar da distância. Chaves tem muito a ver com a América Latina, como um todo. Um menino que não é muito inteligente porque não está bem alimentado. Essa é, sem dúvida, uma realidade. No Brasil também há as vizinhanças como a do Chaves, e, assim como no México, também existem muitas favelas. Apesar do tempo que passou desde que a gente retratou isso no programa, os problemas permanecem (KASCHNER, 2010, p. 123).

Nessa esteira, frisa-se que os roteiros, todos de criação de Chespirito, sendo o ator também, o criador dos demais personagens, destacam algumas situações que podem ser vivenciadas por qualquer um, em qualquer lugar, tendo cada personagem uma característica própria que o deixa mais cativante. Sobre isso, Kaschner (2006, p. 136-137) aponta que:

Os diálogos simples, a modéstia do cenário, o jeito conheço-alguém-assim dos personagens, o humor sem apelação nos faz sentir em casa. Não é impossível que as histórias narradas no programa aconteçam ou tenham acontecido com a gente. Todos nós já conhecemos um Quico, temos uma prima Pópis na família ou já estudamos com um Professor Girafales. Penso que, quando damos gargalhadas com a vila do Chaves, estamos, na verdade, rindo de nós mesmos (KASCHNER, 2006, p. 136-137). 
Desse modo, o seriado Chaves alcança destaque universal por ser, sobretudo, humano, com a inocência de toda criança. Assim, o próprio Roberto Bolaños afirma isso, quando relatou que criou "personagens humanos, cheios de valores e princípios universais, para que qualquer pessoa pudesse se identificar com eles" (KASCHNER, 2006, p. 124).

É importante assinalar que, ao invés de trazer violência, conotação sexual ou qualquer tipo de meio para se conquistar audiência fácil, características que ocorrem na mídia, facilmente, o programa Chaves traz à tona, assuntos como amizade, ingenuidade, questões de egoísmo, fraternidade, vivência em sociedade, amor, perdão, entre outras. Assim, percebem-se valores inerentes ao ser humano e que são transmitidos de forma mais humana possível, fato importante para as crianças que os assistem.

Bolaños, idealizador de criador de Chaves, destaca que a única intenção, ao realizar o seriado, era gerar humor; tal intento é mais um fator que contribui em grande medida ao caráter humano e universal da obra, já que "Não há comicidade fora daquilo que é propriamente humano [...]. Rimos de um animal, mas por termos surpreendido nele uma atitude humana ou uma expressão humana" (BERGSON, 2004, p. 02-03).

O programa que se tornaria um fenômeno mundial, conta a história de um garoto órfão que vive numa vila da periferia de uma grande metrópole latino-americana. Lá, ele convive com vizinhos de diferentes personalidades, com os quais sempre está envolvido em divertidas situações. Classificado por muitos como um programa para crianças, Roberto Bolaños afirmava que suas atrações não tinham cunho infantil. Os textos foram pensados de modo que agradassem a toda a família. Para o autor/ator o programa tem como objetivo despertar o riso e a alegria de maneira saudável, não o isentando de malandragens típicas do ser humano (CARDOSO et al. 2016).

Chaves e Chapolin eram seriados veiculados para a massa, mas que nos trouxeram grandes ensinamentos. A genialidade de Bolaños foi justamente o formato dos programas. Em Chapolin, por exemplo, Bolaños recriava grandes histórias da literatura universal nas mais diversas situações cômicas. E, para nós que não tínhamos grandes acessos à alta cultura, que jamais saberíamos quem era Cantinflas, o exemplo era aquele mesmo ali e pronto. E é justo dizer que não era ruim, pelo contrário (LISBOA, 2014).

No episódio "O ladrão da vila", por exemplo, Bolaños discute o problema do marginal, e o que representa ser marginal em uma sociedade de classes. Chaves, ainda que um menino bom e meigo é um menino de rua. No episódio citado, um ladrão aparece na vila e rouba o ferro de passar de Dona Clotilde. Como os moradores da vila não sabiam do aparecimento de um ladrão, não pensam duas vezes, acusam Chaves de ladrão. Bolaños aqui foi genial, pois trouxe a 
contradição existente na ideia de bom e mal, demonstrando que o mal será sempre aquele que estiver mais próximo da marginalidade (LISBOA, 2014).

Dona Florinda jamais poderia não ser uma mulher mandona e com o cabelo sempre por fazer, afinal ela é mãe solteira, e muitas brasileiras sabem a dificuldade de criar um filho sozinha. Há espaço para cabelos? Há espaços para concretizar seu amor pelo Professor Girafales? Aliás, a figura do Professor Girafales também é genial. Sua pose de "homem das letras", o detentor do conhecimento, o Professor, não deixa de ser usado pela sátira condizente de Bolaños. Qual a figura de um Professor em uma vila periférica? Seus conhecimentos, suas sabedorias fazem algum sentido? É por isso que as aulas realmente não acontecem, é por isso que as nossas aulas, nas escolas públicas pelo Brasil afora, também não acontecem (LISBOA, 2014).

A noção convencional de família se perde, porém, não os laços afetivos. No bairro se reparte a pobreza; se trançam as emoções; se compartilha a desesperança, as brincadeiras, a astúcia, a alegria momentânea. As brigas e agressividade das relações são vencidas pelo carinho. Apesar dos atos hostis, das ações violentas, da analisada indiferença, no ambiente prevalece o positivo (YGLESIAS, 1990).

Pode-se destacar que o êxito alcançado se deve muito ao processo reafirmação da simplicidade, de uma posição estratégica do eu e também da subjetivação da modernidade. Usando a linguagem universal, o humor, a linguagem simples e de fácil compreensão para todos torna Chaves um símbolo que ultrapassou os limites do espaço e do tempo, utilizando-se de estratégias televisivas como a repetição e os roteiros simples e sendo uma grande atração em todos os países que é exibido, reafirmando aspectos de uma rotina presente na vida de milhões de pessoas da América Latina (KASCHNER, 2006).

Em geral, o Programa Chaves apresenta como tema o problema da desigualdade social, da desestrutura familiar e da decadência do ensino. O garoto Chaves, que mal tem o que comer, apresenta-nos o problema da fome. Já o desemprego, é visto na figura do Seu Madruga, que vive de "bicos". E os episódios da escola pública mostram-nos um professor que recebe um baixo salário e alunos pouco interessados. Portanto, interpretar essa realidade que aparece de forma discreta, apresentada por personagens cômicos e piadas ingênuas, torna-nos mais críticos e conscientes (PRADO; GOMES, 2011).

É certo que, ao se observar a relevância do desenvolvimento do pensamento crítico, de modo a deixar que não aconteçam manipulações e alienações, os programas infantis podem trazer muitas informações importantes, com conteúdos pedagógicos. Desse modo, é preciso saber interpretar as mensagens que são transmitidas nos programas infantis e abstrair somente o necessário para aproveitar o que melhor se tem. 
A televisão exerce uma violência simbólica que é inconscientemente exercida ou sofrida. A imprensa sensacionalista, visando ao índice de audiência, despeja em seus telespectadores drama e sexo. No entanto, certa parte da ação simbólica na televisão oferece fatos-ônibus, ou seja, fatos de interesse geral, mas que não formam consenso e não apresentam informações importantes. Embora essas informações apresentem-se como fúteis, elas ocultam preciosidades. E, ao apresentar uma fútil variação de programação, afasta o cidadão de informações pertinentes e dos seus direitos democráticos (BOURDIEU, 1997).

É importante frisar que, segundo Gadotti (2012) o conceito de educação ultrapassa os limites do que se aprende em âmbito escolar, na Educação Básica, do formal, e compreende as experiências de vida e os processos de aprendizagem não-formais, que desenvolvem a autonomia tanto da criança quanto do adulto. Freire (1997, p. 50) destaca que:

[...] se estivesse claro para nós que foi aprendendo que aprendemos ser possível ensinar, teríamos entendido com facilidade a importância das experiências informais nas ruas, nas praças, no trabalho, nas salas de aula das escolas, nos pátios dos recreios, em que variados gestos de alunos, de pessoal administrativo, de pessoal docente se cruzam cheios de significação (FREIRE, 1997, p. 50).

Nesse viés, a educação formal é representada principalmente pelas escolas e universidades, pois depende de uma diretriz educacional centralizada como o currículo, com estruturas hierárquicas e burocráticas, determinadas em nível nacional, com órgãos fiscalizadores do Ministério da Educação. A educação não-formal é mais difusa e não precisa, necessariamente, seguir um sistema sequencial e hierárquico de "progressão", já que é amplo, muitas vezes associado ao conceito de cultura (GADOTTI, 2012).

Logo, o que é transmitido pela mídia pode influenciar positivamente e contribuir em prol dos valores morais às crianças, principalmente por se estar numa época em que os programas televisivos não contêm seu foco voltado para esse expoente, mas ao sensacionalismo, visando à audiência. Roberto Bolaños deixou a todos uma enorme lição, a de "divertir sem causar danos às pessoas, sem distinção de idade, sexo, raça ou nacionalidade" e, sem esperar, perpetuou em todos nós um convite a uma sociedade mais justa, solidária e afetivamente responsável, por meio da célere frase do herói Chapolin Colorado "Sigam-me os bons”! (EDITORIAL TELEVISA, 2012, p. 07).

No episódio intitulado "O ladrão da vila" (CHAVES, 2017, on line) trata-se de uma história bastante significativa, pois, ao surgir um ladrão na vila e furtar muitos dos pertences dos moradores, o garoto Chaves é injustamente acusado do crime pelos integrantes da Vila, deixandoa, e vai até o padre e pede para rezar para que o ladrão se arrependa e devolva tudo, conforme se lê: 
Chaves: então o padre me disse que eu deveria rezar para ficar tudo direito.

Chiquinha: não funcionou porque ainda não encontraram o ladrão.

Chaves: eu não rezei para que encontrassem o ladrão.

Chiquinha: então para quê?

Chaves: rezei para que o ladrão se arrependa e se torne bonzinho (CHAVES, 2017, on line).

Nesta acepção, Costa e Fortuna (2015, on line) aduzem que, "além de provocar risadas, a atração mexicana possui fortes críticas sociais que, embora não tenham sido pensadas para a nossa sociedade, aplicam-se perfeitamente na pós-modernidade". Assim, os programas infantis podem transmitir, ao seu público, valores morais e, de acordo com Vinha e Tognetta (2009, p. 527) é na "convivência diária, desde pequena, com o adulto, com seus pares, com as situações escolares, com os problemas com os quais se defronta, e também experimentando, agindo, que a criança irá construir seus valores, princípios e normas".

A trama arquetípica em Chaves demonstra o quanto o seriado está próximo do mais profundo emocional da sociedade, quando apresenta personagens permeados por arquétipos diversos, mas ainda assim atrelados ao arquétipo clássico de sua faixa etária. Desta maneira, Bolaños caracterizou crianças mais próximas da realidade, dotadas de ingenuidade e curiosidade, diferente dos bebês gênios hollywoodianos, e também criou personagens adultos que vivem em uma realidade atemporal e que é motivo de preocupação, que permeava o mundo na década de 1970 e ainda o faz: a pobreza (OLIVEIRA, 2006).

O Programa Chaves, que é um sucesso até os dias de hoje, porque ele apresenta um diferencial, que é o humor ingênuo e simples, sem a apelação, ultimamente muito encontrada em programas televisivos. O garoto Chaves é órfão e pobre, mas mantém a alegria e a esperança. Seu Madruga, desempregado e sempre devendo o aluguel, tem grande estima por Chaves e tenta ajudá-lo como pode. Seu Madruga tem sempre um "jeitinho brasileiro" de resolver as coisas. E Seu Barriga, dono da vila, que incansavelmente tenta receber os aluguéis atrasados do Seu Madruga, mas, por ter um bom coração, não o despeja (PRADO; GOMES, 2011).

A Chiquinha, filha do Seu Madruga, é uma menina esperta, que está sempre tentando tirar proveitos das coisas. Personagens cômicos, que carregam traços bastante conhecidos em nossa sociedade, remetem-nos à sociedade em que vivemos. Professor Girafales, professor da vila que acredita na transformação do mundo pela educação. Um ponto essencial observado a partir da análise dos episódios é que na vila do Chaves, apesar das muitas brigas e confusões, todos se amam e ajudam-se mutuamente (PRADO; GOMES, 2011).

E o "bem" pode ser observado na figura do Seu Madruga, que sempre tem uma palavra amiga para o pobre Chaves. Diversos episódios apresentam a bondade do Seu Madruga, sua 
solidariedade para com os necessitados, mesmo ele sendo um necessitado. O bom coração do Seu Madruga conquista as pessoas (PRADO; GOMES, 2011).

Por sua vez, os valores morais podem se constituir como horizontes normativos considerados bons para vivência em sociedade, como por exemplo, solidariedade, respeito mútuo, justiça, cooperação, amor (FUCHS, 2005). Por esse caminho, em relação à moralidade, La Taille (2007, p. 02), a define como “[...] processos psíquicos por meio dos quais se legitimam regras, princípios de valores morais, entende-se por moral aquilo que é da ordem do dever".

Destarte, a mídia aparece como central na articulação da hegemonia, sendo o aparelho privado que mais incide na formação de uma direção moral e intelectual da sociedade (LIMA, 2004). Considerando que a ética e a moral permeiam a conduta humana, quer na vida pessoal quer na vida profissional, faz-se necessário refletir acerca dos valores morais e da relevância que estes adquirem na sociedade e como são percebidos pelos indivíduos nela inseridos, assim como os valores disseminados na mídia televisiva brasileira (SANTANA; MERCADO, 2011).

Segundo Bourdieu (1997, p. 141), a televisão busca a guerra de audiência, incansável e insensata que gera "uma representação do mundo prenhe de uma filosofia da história como sucessão absurda de desastres sobre os quais não se compreende nada e sobre os quais não se pode nada", gerando a ausência de valores e de um público que não reflete e não anseia por uma moral, como se nada significassem ou nada representassem, construindo o que Adorno (1995) denomina de espetacularização da imprensa.

Em resumo, pode-se depreender que o seriado Chaves aviva a uma atenção característica da realidade vivenciada pelos infantes, no Brasil e no mundo, não somente ilustrando o cenário da fome e abandono, mas, especialmente, o modo de superar as situações de superação dessas e de outros problemas, relevando a convivência em comunidade. Nesse sentido, pode-se vislumbrar que o seriado desempenha um papel participativo que ajuda na formação moral, humana e na educação das crianças.

Assim, além desses fatores, o êxito não repousa somente na qualidade dos atores, tampouco apenas nos critérios de humor empregados no roteiro, mas, também, no reconhecimento do público com a solidariedade aos entraves vividos pelos personagens, que, mesmo retratados em meados dos anos 1970, podem ser aplicadas na hodiernidade dos contrastes da sociedade, desigualdades e pobreza insertos em nossa rotina.

Por outro prisma, é latente a concepção cultural manifesta no seriado, que privilegia a constituição do caráter infantil, uma vez que se percebem diversos valores humanos que são transmitidos ao público, tais como a solidariedade, o afeto, o amor fraternal, a sensibilidade com a dor alheia, o compartilhamento, o perdão, entre outros. Tais fatores podem contribuir com os valores morais às crianças, devido ao cunho pedagógico que baliza o meio de comunicação. 
Ademais, o ser justo, solidário e esperançoso adjetiva a trama e se fortifica ante ao público, acatando o artigo 221, inciso I, da Constituição da República Federativa do Brasil, que testifica que a "produção e a programação das emissoras de rádio e televisão atenderão aos seguintes princípios da preferência a finalidades educativas, artísticas, culturais e informativas e ao respeito aos valores éticos e sociais da pessoa e da família” (BRASIL, 1988).

Portanto, são notórios os vínculos de amizade entre as crianças no seriado, mesmo nos momentos difíceis que caracterizam a história de cada um. Além disso, é importante a representação que os personagens adultos têm, como Seu Madruga e o Professor Girafales, servindo de parâmetro e ensinando-os o respeito ao próximo e obediência, mesmo com seu modo satírico e artístico, contudo, com simples alusão à existência paterna.

Em suma, pode-se abstrair do exposto que, as lições morais tangenciam o sujeito a desenvolver suas virtudes e valores morais, ressaltando, fundamentalmente, os fatores endógenos e exógenos, ajudando-o a construir internamente e coletivamente suas relações sociais e aos valores morais e éticos.

\section{CONSIDERAÇÕES FINAIS}

Para todos aqueles que estão próximos das crianças no dia a dia, como os pais, educadores e responsáveis é difícil deixar de lado a importância grandiosa da mídia. O público infantil fica muito tempo entretido com os meios de comunicação o que a companhia de outras pessoas e é por tal motivo o que é necessário estar atento ao conteúdo pagado, para que não se exerça uma influência negativa nos infantes.

Assim, destacou-se no presente estudo, que se deve rever e repensar relacionados a tecnologia, as crianças têm fácil acesso e aprender mais rápido a lidar com a era digital do que os adultos. A mídia em geral pode gerar conteúdos e tornar as crianças mais alienadas e consumistas, deixando um aspecto negativo no que diz respeito os valores morais e éticos.

Destacou-se, então, que a televisão é um meio de comunicação que diverte, a partir do irreal com a realidade. Logo, ressaltou-se o relevo de se suscitar o pensamento crítico às crianças, de modo a diferenciar o fictício do real. Dessa forma, destacou-se o seriado mexicano "Chaves", no ar, no país, há mais de trinta anos, cujo conteúdo de suas narrativas transmitirem temas sociais, como a fome e a educação, exibidos em meio a piadas inocentes e personagens cômicos.

Procurou-se, assim, permear o que é transmitido pelos personagens, no tocante à crítica social, numa época em que o fato de se ficar em casa se tornou essencial, devido a fase pandêmica que assola à sociedade. Assim, vislumbra-se a importância do que os conteúdos midiáticos oferecem às crianças, especialmente no que tem a contribuir em relação aos valores morais. 
Abordou-se que, a série em questão, auxilia nesse sentido, pois transmite aos espectadores cenas relacionadas ao estímulo do perdão, à solidariedade, ao amor fraternal, à sensibilidade em relação à dor alheia, aos conceitos de higiene, ao compartilhamento, entre outros, o que se percebe nos diálogos dos personagens, quanto nas atitudes, o que permite constatar várias características culturais que podem influenciar nossos valores.

Portanto, o Programa do Chaves tenta trazer os valores no ser humano, fato de suma importância para a educação das crianças, o que desperta o espírito de brincar, sem qualquer tipo de malícia, com humor ingênuo e comum, sem apelar, fato que, ultimamente, muito se encontra em alguns programas televisivos.

Nesse viés, as histórias remetem à sociedade, com personagens de características distintas e cada um com sua marca própria, como a do professor que crê na transformação do mundo pela educação. Por fim, apresenta-se a realidade social aliada a muita piada, mas, o mais importante é remeter aos valores, como a ética e a amizade, para que o público assista sem deixar-se manipular e alienar.

\section{REFERÊNCIAS}

ADORNO, Sérgio. Violência, ficção e realidade. In: SOUZA, Mauro W. (Org.). Sujeito: o lado oculto do receptor. São Paulo: Brasiliense, 1995.

ADORNO, Theodor W. Gesammelte Schriften. Frankfurt a.M.: Suhrkamp, 1970. 20v.

BELLONI, Maria Luiza. O que é mídia-educação. Campinas: Autores Associados (Coleção Polêmicas do Nosso Tempo). 2001.

BERGER, Peter; LUCKMANN, Thomas. A construção social da realidade. Petrópolis: Vozes, 1978.

BERGSON, Henri. O riso. Ensaio sobre a significação da comicidade. Tradução Ivone Castilho Benedetti. São Paulo: Martins Fontes, 2004.

BOURDIEU, Pierre. Sobre a televisão. Rio de Janeiro, RJ: Jorge Zahar Editor, 1997.

BRASIL. Constituição (1988). Constituição da República Federativa do Brasil, Brasília, DF, Senado, 1988.

CARDOSO, Alessandro; BIASETTO, Isabelle; SELLA, Marcos; MATOS, Paulina; BONA, Tatiana; TAVARES, Renato. Barril do Chaves. Intercom - Sociedade Brasileira de Estudos Interdisciplinares da Comunicação XXIII Prêmio Expocom 2016 - Exposição da Pesquisa Experimental em Comunicação.2016.

CHAVES. O ladrão da vila. Disponível em:

<https://www.youtube.com/watch?v=Lj6g79fcZd4>. Acesso em 26 mai. 2020. 
CITELLI, Adílson. (coord.). Outras linguagens na escola: publicidade, cinema e TV, rádio, jogos e informática. $4^{\mathrm{a}}$ Ed. São Paulo: Cortez. (Coleção aprender e ensinar com textos; v. 6). Vários autores. 2004.

EDITORIAL TELEVISA. Chaves: a história oficial ilustrada. Tradução de Maurício Tamboni. São Paulo: Universo dos Livros, 2012.

FREIRE, Paulo. Pedagogia da autonomia: saberes necessários à prática educativa. São Paulo: Paz e Terra. 1997.

FUCHS, Ana Carolina Muller. Improvisação teatral e descentração. 91f. Dissertação (Mestrado em Educação). Universidade Federal do Rio Grande do Sul, Rio Grande do Sul, RS/Brasil. 2005.

GADOTTI, Moacir. Educação popular, educação social, educação comunitária. In: Congresso Internacional de Pedagogia Social. 2012.

GREENFIELD, Patrícia Marks. O desenvolvimento do raciocínio na era eletrônica: os efeitos da tv, computadores e videogames. Summus, 1988. (tradução brasileira).

HUREMOVIĆ, Damir. Social distancing, quarantine, and isolation. In: Huremović D, ed. Psychiatry of pandemics. Cham: Springer; 2019. p. 85-94.

KASCHNER, Pablo. Chaves de um sucesso. Rio de Janeiro: Editora Senac Rio, 2006.

KASCHNER, Pablo. Seu Madruga: vila e obra. Rio de Janeiro: Mirabolantes, 2010.

LA TAILLE, Yves. Desenvolvimento humano: contribuições da psicologia moral. Instituto de psicologia - USP. 18 (1), 11-36, 2007.

LIMA, Venício A. de. Mídia: teoria e política. São Paulo: Fundação Perseu Abramo, 2004.

LISBOA, Larissa. Livre Opinião. A genialidade de Bolaños. 2014. Disponível em <http://livreopiniao.com/2014/12/01/a-genialidade-de-bolanos/>. Acesso em 08 nov. 2019.

MELLO, Guiomar Namo de. Ofício de Professor: aprender mais para ensinar melhor. São Paulo: Fundação Victor Civita, v. 8, 2002.

MERCADO, Luís Prado Leopoldo (org.). Novas tecnologias na educação: reflexões sobre a prática. Maceió: EDUFAL, 2002.

MOREIRA, Alberto da Silva. Cultura midiática e educação infantil. Educ. Soc, v. 24, n. 85, p. 1203-1235, 2003.

OLIVEIRA, Rafael Menezes. Razões para a permanência do seriado Chaves no Brasil. 2006.

PACHECO, Elza (org.). Televisão, criança, imaginário e educação. 5. ed. Campinas: Papirus, 2009.

POPPER, Karl; CONDRY, John. Televisão: um perigo para a democracia. $3^{\text {a }}$ ed. Tradução por Maria Carvalho. Lisboa: Gradiva, 2007. 
PRADO, Lilian Santos de Godoy; GOMES, Ana Claudia Fernandes. Representações simbólicas da sociedade: Estudo do programa chaves. Iniciação Científica Cesumar, v. 13, n. 1, 2011.

SANCHES, Raquel Cristina Ferraroni; LEONARDO, Francisco Antonio Morilhe. O amor, direitos humanos e constituição. Revista Brasileira de Estudos Políticos, v. 113, 2016.

SANTANA, Clésia Maria Hora; MERCADO, Luís Paulo Leopoldo. A mídia televisiva e a transmissão de valores na ótica de alunos do Ensino Médio. Educ. rev., Curitiba, n. 42, p. 263 277, dez. 2011.

SILVA, Antonio Luiz da; FERREIRA, Núbia Guedes de Barros. Além da culpa e da expiação: Covid-19 e as fissuras de gramáticas emocionais. RBSE Revista Brasileira de Sociologia da Emoção, v. 19, n. 55, abril de 2020. Suplemento Especial - Pensando a Pandemia à luz da Antropologia e da Sociologia das Emoções, pp. 175-185, maio de 2020 - ISSN 1676-8965.

SILVA, Arlindo. A fantástica história de Silvio Santos. São Paulo: Editora do Brasil, 2002.

SOIFER, Raquel. A criança e a TV: uma visão psicanalítica. Tradução Iara Rodrigues. Porto Alegre: Artes Médicas, 1991.

VALLADARES, Ricardo. Entrevista com Roberto Bolaños. Veja. São Paulo: Abril, 20 out. 1999.

YGLESIAS, María Perez. EI Chavo del Ocho, ¿Por que lo aman los ninõs? Revista Herencia Editorial de la Universidad de Costa Rica (UCR), set.1990.

WHO. World Health Organization (WHO). Coronavirus disease (COVID-19) pandemic [Internet]. Geneva: WHO; 2020. Disponível em:

https://www.who.int/emergencies/diseases/novel-coronavirus-2019. Acesso em 23 mai 2020. 